\title{
Serological Markers of Enterocyte Damage and Apoptosis in Patients With Celiac Disease, Autoimmune Diabetes Mellitus and Diabetes Mellitus Type 2
}

\author{
I. HOFFMANOVÁ ${ }^{1}$, D. SÁNCHEZ ${ }^{2}$, V. HÁBOVÁ ${ }^{2}$, M. ANDĚL ${ }^{1}$, L. TUČKOVÁ ${ }^{2}$, \\ H. TLASKALOVÁ-HOGENOVÁ ${ }^{2}$
}

${ }^{1}$ Second Department of Internal Medicine, Third Faculty of Medicine, Charles University in Prague, Prague, Czech Republic, ${ }^{2}$ Laboratory of Cellular and Molecular Immunology, Institute of Microbiology, Czech Academy of Sciences, Prague, Czech Republic

Received September 24, 2014

Accepted October 6, 2014

On-line December 3, 2014

\begin{abstract}
Summary
Impairment of mucosal barrier integrity of small intestine might be causative in immune-mediated gastrointestinal diseases. We tested the markers of epithelial apoptosis - cytokeratin 18 caspase-cleaved fragment (CCK-18), and enterocyte damage intestinal fatty acid-binding protein (I-FABP) and soluble CD14 (SCD14) in sera of patients with untreated celiac disease (CLD), those on gluten-free diet (CLD-GFD), patients with autoimmune diabetes mellitus (T1D), T1D with insulitis (T1D/INS), and diabetes mellitus type 2 (T2D). We found elevated levels of CCK$18(\mathrm{P}<0.001)$, I-FABP $(\mathrm{P}<0.01)$ and $\mathrm{SCD} 14(\mathrm{P}<0.05)$ in $\mathrm{CLD}$ when compared to healthy controls. However, the levels of CCK$18(P<0.01)$ and I-FABP $(P<0.01)$ in CLD-GFD were higher when compared with controls. Interestingly, elevated levels of $\mathrm{CCK}-18$ and I-FABP were found in T2D and T1D $(P<0.001)$, and T1D/INS $(P<0.01, P<0.001)$. Twenty-two out of 43 CLD patients were seropositive for CCK-18, 19/43 for I-FABP and 11/43 for SCD14; $9 / 30$ of T2D patients were positive for CCK-18 and 5/20 of T1D/INS for SCD14, while in controls only $3 / 41$ were positive for cCK-18, 3/41 for I-FABP and 1/41 for SCD14. We documented for the first time seropositivity for SCD14 in CLD and potential usefulness of serum CCK-18 and I-FABP as markers of gut damage in CLD, CLD-GFD, and diabetes.
\end{abstract}

\section{Key words}

Cytokeratin 18 caspase-cleaved fragment - Intestinal fatty acidbinding protein - Soluble CD14 - Intestinal barrier • Autoimmunity

\section{Corresponding author}

D. Sánchez, Department of Immunology, Institute of Microbiology, v.v.i., Czech Academy of Sciences, Vídeňská 1083, 14220 Prague, Czech Republic. Fax: +420 241062458. E-mail: sanchez@biomed.cas.cz

\section{Introduction}

Chronic impairment of gut status and intestinal mucosal barrier integrity associated with increased enterocyte apoptosis and damage might be causative in the development of inflammatory and immune-mediated gastrointestinal diseases (Fasano and Shea-Donohue 2005). Celiac disease (CLD) represents a specific kind of immune-mediated intolerance of dietary wheat gluten with autoimmune features. Ingestion of water-insoluble fraction of gluten - gliadin triggers the enteropathy and damage of the small-gut mucosal barrier in genetically susceptible individuals. Life-long adherence to gluten-free diet (GFD) enables the regeneration of small-gut mucosa in CLD patients and prevents more severe forms of CLD and the development of autoimmune complications targeting various organs. The relevance of precise, early and noninvasive diagnostics of CLD and reliable markers for monitoring the disease course are essential since this disease is frequently associated with severe autoimmune endocrine, liver and rheumatologic disorders, T-cell lymphoma and reproductive insufficiency, as well as with a high population frequency of CLD estimated at 1:250- 
500 (Trier 1991, Husby et al. 2012).

The relationship between CLD and autoimmune diabetes mellitus (T1D) is intensively studied due to putatively associated etiopathogenesis (Lettre and Rioux 2008). The common features of CLD and T1D documented by genome-wide association study (GWAS) suggested the role of impaired mucosal barrier function in etiopathogenesis of both diseases (Zhernakova et al. 2013). The prevalence of CLD among patients with T1D has been estimated at approximately $4 \%$ (range from $2 \%$ to $11 \%$ ). The risk of co-morbidity with CLD is high at the onset of T1D, in children younger than 4 years, and increases with the duration of diabetes (Cerutti et al. 2004, Salardi et al. 2008, Pham-Short et al. 2012). In our previous study, $10.3 \%$ of Libyan children with T1D had biopsy-based clear histological evidence of CLD (Ashabani et al. 2003). The hypothesis linking the pathogenesis of the two diseases is supported also by partially shared HLA haplotypes - HLA-DQ2 and HLADQ8 in CLD and some T1D patients (Rewers et al. 2004, Rewers and Eisenbarth 2011, Hummel et al. 2011). It is assumed that the penetration of luminal components or pathogens from "leaky" gut in untreated CLD patients may alter the function of $\beta$-cells or induce insulitis (Yajima et al. 2009, Kuo et al. 2010, Wang et al. 2010, Peng and Hagopian 2006). Increased translocation of food and microbial antigens from gut lumen into circulation in untreated CLD patients but also in individuals with impaired intestinal barrier function has long been presumed to activate immune response and to trigger and/or potentiate $\beta$-cell inflammatory destruction preceding clinical manifestation of T1D (Peng and Hagopian 2006, Knip et al. 2005, Knip and Simell 2012, Tlaskalová-Hogenová et al. 2011, Funda et al. 2001, Osterbye et al. 2010, Kučera et al. 2003). The contribution of immune system to diabetes pathogenesis is documented by analysis of enterobiopsies in T1D patients in whom elevated levels of IFN- $\gamma$ and TNF- $\alpha$ were found indicating pro-inflammatory conditions in the gut mucosa. In these patients, the production of high levels of IL-17 by peripheral $\mathrm{CD} 45 \mathrm{RA}^{-} \mathrm{CD} 25^{\mathrm{int}} \mathrm{CD} 4^{+} \mathrm{T}$ cells and $\mathrm{CD}^{+} \mathrm{T}$ cells after activation with antiCD3/CD28 antibodies was detected (Bruewer et al. 2005, Li et al. 2008, Westerholm-Ormio et al. 2003). The increasing intestinal permeability measured by lactulose/mannitol significantly correlated with luminal levels of zonulin i.e. protein modulating epithelial tight junctions (Vaarala 2008). On the other hand, it is known that only the proportion of saturated fatty acids and polyunsaturated fatty acids in dietary intake is sufficient for affecting the systemic inflammation (Králová Lesná et al. 2013). Interestingly, also diabetes mellitus type 2 (T2D) is associated with increased inflammatory response, which is modulated by intestinal microbiota and nutritional composition (Musso et al. 2010).

In this study we analyzed and compared the serum levels of cytokeratin 18 caspase-cleaved fragment (cCK-18) as a marker of epithelial apoptosis and intestinal fatty acid-binding protein (I-FABP) as indicator of enterocyte damage (Derikx et al. 2008, Adriaanse et al. 2013) in patients with newly diagnosed (untreated) CLD, CLD treated with GFD (CLD-GFD), T1D with insulitis (T1D/INS), T1D with fading insulitis (T1D), T2D, and healthy controls. Moreover, the testing of soluble CD14 (sCD14) was used as an indicator of activation of innate immunity cells in response to mucosal translocation of gram-negative bacteria or their components in these patients (Ancuta et al. 2008).

\section{Materials and Methods}

\section{Patients and healthy donors}

Table 1 summarizes baseline characteristics of tested patients with CLD, CLD-GFD, T1D/INS, T1D, T2D, and healthy controls. The CLD patients were diagnosed in accordance with modified ESPGHAN criteria (Husby et al. 2012), i.e. they were seropositive for IgA anti-tissue transglutaminase (anti-tTG) antibodies (Ab) and IgA and IgG anti-endomysial Ab (EMA), and pathological changes of their small bowel mucosa were classified as Marsh IIIA-C. Sera of CLD-GFD patients collected after at least 12 months of adherence to GFD were negative for EMA and anti-tTG Ab; all of these patients were free of symptoms of CLD. The Ab to tyrosine phosphatase-like insulinoma antigen 2 (anti-IA2) and $\mathrm{Ab}$ to glutamic acid decarboxylase (anti-GAD) were used for discriminating between T1D/INS and T1D (Wenzlau et al. 2007, Nokoff et al. 2012). The cohort of healthy controls represents blood donors.

The serological testing and histological analysis were routinely performed in Department of Laboratory Medicine and Department of Pathology, Faculty Hospital Královské Vinohrady in Prague. ELISA kit IgA (Biosystems SA, Barcelona, Spain) for the estimation of levels of serum anti-tTG Ab, indirect immunofluorescence - monkey esophagus (AEA - Anti Endomysium antibodies, Biosystems SA, Barcelona, Spain) for IgA, IgG EMA, Medizym Anti-GAD ELISA kit for anti-GAD 
$\mathrm{Ab}$ and Medizin Anti-IA2 ELISA kit (MEDIPAN GMBH, Dahlewitz/Berlin, Germany) for anti-IA2 Ab, Immulite 2000, Siemens Healthcare Diagnostics and ADVIA Centaur XP, Siemens Healthcare Diagnostics for anti-thyroid peroxidase $\mathrm{Ab}$ and anti-human thyroglobulin $\mathrm{Ab}$ was used. The serum levels of immunoglobulins were measured by employing nephelometry (BNII analyzer, Dade Behring - Siemens), albumin using a colorimetric assay with bromocresol green and ADVIA 1800 and Cobas 8000 and Cobas 6000 analyzer (Siemens
Healthcare Diagnostics, and Roche Diagnostics), and the levels of C-reactive protein (CRP) by immuneturbidimetry (Siemens Healthcare Diagnostics, and Roche Diagnostics). The data are expressed as mean \pm standard error. The ALT and AST serum levels were tested using IFCC with pyridoxal-5-phosphate and ADVIA 1800 (Siemens Healthcare Diagnostics). Liver steatosis was evaluated by abdominal ultrasonography (data not shown).

Table 1. Baseline characteristics of patients and controls.

\begin{tabular}{|c|c|c|c|c|c|c|}
\hline Cohorts & $\mathbf{C}$ & CLD & CLD-GFD & T1D/INS & T1D & T2D \\
\hline Number & 41 & 43 & 12 & 20 & 20 & 30 \\
\hline Mean age/range & $39.4(18-81)$ & $30.8(18-46)$ & $41.2(22-77)$ & $53.5(20-87)$ & $47.1(20-78)$ & $66.3(41-84)$ \\
\hline Gender ratio $(F / M)$ & $19 / 22$ & $27 / 16$ & $8 / 4$ & $7 / 13$ & $9 / 11$ & $12 / 18$ \\
\hline Histology: Marsh & N.D. & IIIA-C & N.D. & N.D. & N.D. & N.D. \\
\hline \multicolumn{7}{|l|}{ Antibodies } \\
\hline anti-tTG $\operatorname{Ig} A$ & $0.6 \pm 0.3$ & $105.9 \pm 22.75$ & $2.7 \pm 0.69$ & $1.0 \pm 0.24$ & $3.0 \pm 1.3$ & $1.4 \pm 0.3$ \\
\hline$E M A$ & negative & positive & negative & negative & negative & negative \\
\hline Anti-GAD & $2.7 \pm 2.1$ & $1.4 \pm 0.58$ & $1.4 \pm 1.1$ & $120.8 \pm 23.4$ & $1.8 \pm 0.5$ & $1.2 \pm 0.5$ \\
\hline Anti-IA-2 & $2.0 \pm 0.4$ & $3.6 \pm 1.5$ & $0.9 \pm 0.6$ & $40.3 \pm 20.1$ & $0.7 \pm 0.4$ & $0.5 \pm 0.5$ \\
\hline Anti-TPO (F/M) & negative & $2(1 / 1)$ & negative & $5(1 / 4)$ & $5(3 / 2)$ & $1(0 / 1)$ \\
\hline Anti-hTG (F/M) & negative & $2(1 / 1)$ & negative & $2(0 / 2)$ & $2(2 / 0)$ & $1(0 / 1)$ \\
\hline \multicolumn{7}{|l|}{ Total serum levels } \\
\hline Albumin & $43.2 \pm 0.3$ & $42.4 \pm 0.79$ & $43 \pm 1.1$ & $36.9 \pm 0.9$ & $37.0 \pm 1.0$ & $39.2 \pm 0.8$ \\
\hline$C R P$ & $3.1 \pm 0.6$ & $5.0 \pm 1.7$ & $4.1 \pm 1.1$ & $15.7 \pm 4.9$ & $5.7 \pm 2.0$ & $5.1 \pm 0.9$ \\
\hline $\operatorname{Ig} A$ & $2.1 \pm 0.1$ & $2.4 \pm 0.2$ & $1.8 \pm 0.2$ & $2.6 \pm 0.3$ & $2.5 \pm 0.2$ & $3.1 \pm 0.3$ \\
\hline $\operatorname{IgG}$ & $10.9 \pm 0.3$ & $11.6 \pm 0.74$ & $10.3 \pm 0.9$ & $11.4 \pm 1.0$ & $9.8 \pm 0.9$ & $9.4 \pm 0.5$ \\
\hline $\operatorname{Ig} M$ & $1.1 \pm 0.1$ & $1.4 \pm 0.2$ & $1.5 \pm 0.3$ & $1.1 \pm 0.2$ & $1.1 \pm 0.1$ & $0.9 \pm 0.1$ \\
\hline $\operatorname{Ig} E$ & $63.8 \pm 8.7$ & $76.5 \pm 35.9$ & $131.0 \pm 98.5$ & $57.2 \pm 15.9$ & $106.6 \pm 36.0$ & $127.4 \pm 49.9$ \\
\hline
\end{tabular}

C, healhy controls; CLD, active celiac disease; CLD-GFD, celiac disease on gluten-free diet; T1D/INS, autoimmune diabetes mellitus with insulitis; T1D, autoimmune diabetes mellitus with fading insulitis; T2D, diabetes mellitus type 2; $F$, female; $M$, male; tTG, tissue transglutaminase; EMA, endomysial antibodies; Marsh (Marsh classification); GAD, glutamic acid decarboxylase; IA-2, islet antigen-2; TPO, thyroid peroxidase; hTG, human thyroglobulin; CRP, C-reactive protein. Physiological values: IgA anti-tTG $\left(\right.$ Ab $<12.00$ IU.ml $\left.{ }^{-1}\right)$,

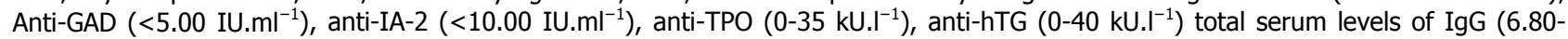

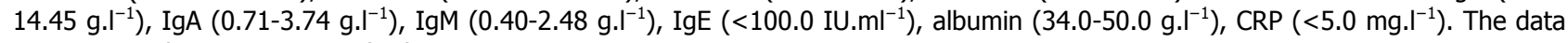
are expressed as mean \pm standard error.

None of the individuals from control group had autoimmune, inflammatory, malignant or infectious disease at the time of blood taking. The patients with T1D/INS, T1D and T2D associated with severe complications were excluded in the study, as well as patients having other chronic diseases, malignant disease, IgA-deficiency or abnormal levels of liver enzymes
(ALT, AST). None of healthy controls and patients with diabetes was positive for anti-tTG Ab and EMA in this study. The study was reviewed and approved by the Local Ethics Committee from the Faculty Hospital Královské Vinohrady in Prague (Czech Republic). Written informed consent was obtained from each participant in the study. 


\section{cCK-18, I-FABP and SCD14 ELISA}

The sera of patient and control groups were tested for cCK-18 using M30-Apoptosense ELISA (Peviva, Sweden), for I-FABP by Human, I-FABP ELISA Kit (Hycult Biotech Inc., USA), and for sCD14 by Human sCD14 ELISA Kit, (Hycult Biotech Inc., USA) according to the manufacturer's instructions.

a

cCK-18

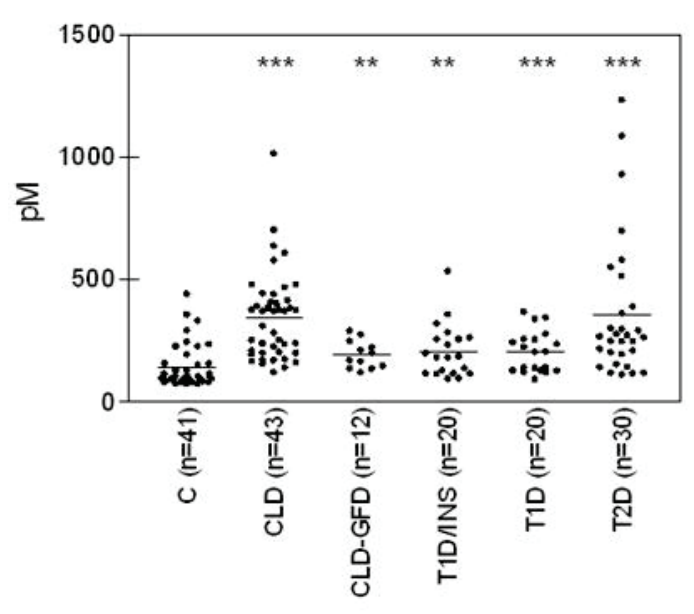

C

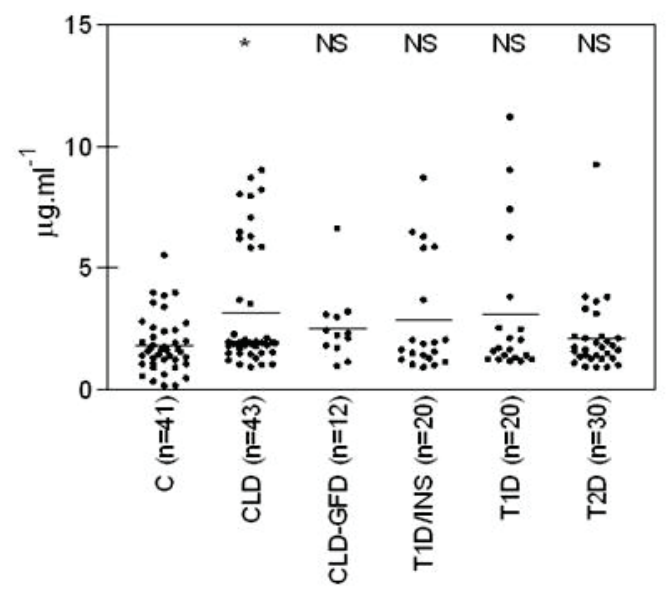

Statistical analysis

The cut-off values for cCK-18, I-FABP and sCD14 were calculated as the mean value plus 2 standard deviations (SD) of serum levels of individual markers tested in 41 healthy controls. The Mann-Whitney U-test was used to compare the serum levels of tested markers among groups of patients and controls.

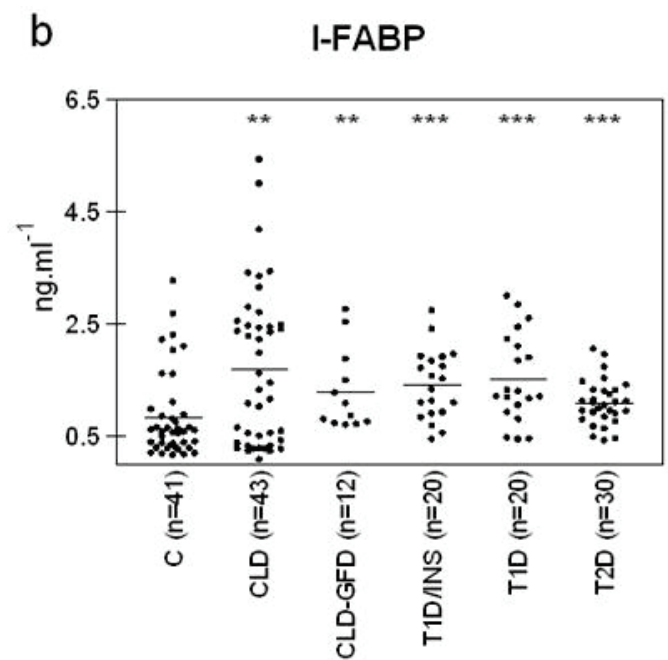

Fig. 1. Individual distribution of CCK-18, cytokeratin 18 caspase-cleaved fragment (a), I-FABP, intestinal fatty acid-binding protein (b), sCD14, soluble CD14 (c) in patients with untreated celiac disease (CLD), celiac disease patients on gluten-free diet (CLD-GFD), autoimmune diabetes mellitus with insulitis (T1D/INS), autoimmune diabetes mellitus with fading insulitis (T1D), diabetes mellitus type 2 (T2D) and healthy controls (C). Solid lines represent the mean value; $n$, number of patients and controls; $* * *(P<0.001)$, $* *(P<0.01), *(P<0.05) ; N S$, not significant. The values above cut-off (which equals $310 \mathrm{pM}$ for cCK-18, $2.2 \mathrm{ng}^{\mathrm{m} \mathrm{l}^{-1}}$ for I-FABP and $4.2 \mu \mathrm{g} \cdot \mathrm{ml}^{-1}$ for $\left.\mathrm{SCD} 14\right)$ are considered positive.

\section{Results}

The occurrence of the markers cCK-18, I-FABP and SCD14 was tested in sera from 166 individuals including five groups of patients with: CLD, CLD-GFD, T1D/INS, T1D, T2D, and healthy controls. Figure $1 \mathrm{a}, \mathrm{b}$, $\mathrm{c}$ documents individual distribution of serum levels of the tested markers. Table 2 summarizes the serum levels of tested markers in patient and control groups and statistical evaluation. All serological markers were significantly increased in patients with untreated CLD: cCK-18 $\quad(\mathrm{P}<0.001), \quad$ I-FABP $\quad(\mathrm{P}<0.01) \quad$ and $\quad \mathrm{sCD} 14$ $(\mathrm{P}<0.05)$ in contrast to healthy controls. In these patients the mean levels of the tested markers reached the highest 
values: cCK-18 (339.3 $\pm 178.4 \mathrm{pM}$; mean \pm SD), I-FABP $\left(1.7 \pm 1.4\right.$ ng. $\left.\mathrm{ml}^{-1}\right), \mathrm{sCD} 14\left(3.2 \pm 2.5 \mu \mathrm{g} \cdot \mathrm{ml}^{-1}\right)$, whereas the values in healthy controls were $137.2 \pm 86.3 \mathrm{pM}$ (cCK-18), $0.8 \pm 0.7 \mathrm{ng} \cdot \mathrm{ml}^{-1}$ (I-FABP), and $1.8 \pm 1.2 \mu \mathrm{g} \cdot \mathrm{ml}^{-1}$ (sCD14). The serum levels of tested markers were substantially diminished in patients with CLD-GFD compared with untreated CLD. However, slightly elevated levels of cCK-18 $(\mathrm{P}<0.01)$ and I-FABP $(\mathrm{P}<0.01)$, in contrast to healthy controls, persisted even if these patients strictly adhered to GFD. Table 3 presents the fractions of seropositive individuals who exceeded cut-off values for cCK-18, I-FABP and sCD14 in tested groups. The values above cut-off (which equals 310 pM for cCK-18,
2.2 ng. $\mathrm{ml}^{-1}$ for I-FABP and $4.2 \mu \mathrm{g} \cdot \mathrm{ml}^{-1}$ for sCD14) are considered positive. While the fraction of seropositive patients with active CLD was 22 out of 43 for cCK-18, $19 / 43$ for I-FABP and $11 / 43$ for sCD14, none out of 12 patients with CLD-GFD was seropositive for cCK-18 and only 2 patients from this group for I-FABP and one patient for sCD14. Among patients groups, significantly increased serum levels of sCD14 were found only in cohort of untreated CLD patients, yet 5 out of 20 patients with T1D/INS were also seropositive for this marker. In healthy controls group, only 3 out of 41 were positive for cCK-18, 3/41 for I-FABP and 1/41 for sCD14.

Table 2. Comparison of CCK-18, I-FABP and SCD14 levels in sera of adult patients with untreated celiac disease, those on gluten-free diet, autoimmune diabetes mellitus with insulitis and those with fading insulitis and diabetes mellitus type 2 (Mann-Whitney test).

\begin{tabular}{lcccccc}
\hline Markers & C & CLD & CLD-GFD & T1D/INS & T1D & T2D \\
\hline \multirow{2}{*}{$c$ CK-18 } & $137.2 \pm 86.3$ & $339.3 \pm 178.4$ & $189.3 \pm 57.1$ & $204.1 \pm 109.5$ & $200.5 \pm 84.3$ & $355.4 \pm 287.5$ \\
& - & $\mathrm{P}<0.001$ & $\mathrm{P}<0.01$ & $\mathrm{P}<0.01$ & $\mathrm{P}<0.001$ & $\mathrm{P}<0.001$ \\
$I-F A B P$ & $0.8 \pm 0.7$ & $1.7 \pm 1.4$ & $1.3 \pm 0.7$ & $1.4 \pm 0.7$ & $1.5 \pm 0.8$ & $1.1 \pm 0.4$ \\
& - & $\mathrm{P}<0.01$ & $\mathrm{P}<0.01$ & $\mathrm{P}<0.001$ & $\mathrm{P}<0.001$ & $\mathrm{P}<0.001$ \\
\multirow{2}{*}{ CD14 } & $1.8 \pm 1.2$ & $3.2 \pm 2.5$ & $2.5 \pm 1.5$ & $2.6 \pm 2.4$ & $3.1 \pm 3.0$ & $2.1 \pm 1.6$ \\
& - & $\mathrm{P}<0.05$ & $\mathrm{NS}$ & $\mathrm{NS}$ & $\mathrm{NS}$ & $\mathrm{NS}$ \\
\hline
\end{tabular}

C, healthy controls; CLD, celiac disease; CLD-GFD, celiac disease on gluten-free diet; T1D/INS autoimmune diabetes mellitus with insulitis; T1D, autoimmune diabetes mellitus with fading insulitis; T2D, diabetes mellitus type 2; cCK-18, cytokeratin 18 caspase-cleaved fragment (pM); I-FABP, intestinal fatty acid-binding protein $\left(\mathrm{ng} \cdot \mathrm{ml}^{-1}\right)$; $\mathrm{sCD} 14$, soluble $\mathrm{CD} 14\left(\mu \mathrm{g} \cdot \mathrm{ml}^{-1}\right)$. The data are expressed as mean \pm standard deviation.

Table 3. The frequency of seropositivity for CCK-18, I-FABP and SCD14 in adult patients with untreated celiac disease, those on glutenfree diet, autoimmune diabetes mellitus with insulitis and those with fading insulitis and diabetes mellitus type 2.

\begin{tabular}{lcccccc}
\hline Markers & C & CLD & CLD-GFD & T1D/INS & T1D & T2D \\
\hline$c C K-18$ & $3 / 41(7.3 \%)$ & $22 / 43(51.1 \%)$ & $0 / 12(0 \%)$ & $3 / 20(15 \%)$ & $3 / 20(15 \%)$ & $9 / 30(30 \%)$ \\
$I-F A B P$ & $3 / 41(7.3 \%)$ & $19 / 43(44.2 \%)$ & $2 / 12(16.7 \%)$ & $2 / 20(10 \%)$ & $5 / 20(25 \%)$ & $0 / 30(0 \%)$ \\
$s C D 14$ & $1 / 41(2.4 \%)$ & $11 / 43(25.6 \%)$ & $1 / 12(8.3 \%)$ & $5 / 20(25 \%)$ & $4 / 20(20 \%)$ & $1 / 30(3.3 \%)$ \\
\hline
\end{tabular}

C, healhy controls; CLD, celiac disease; CLD-GFD, celiac disease on gluten-free diet; T1D/INS, autoimmune diabetes mellitus with insulitis; T1D, autoimmune diabetes mellitus with fading insulitis; T2D, diabetes mellitus type 2; cCK-18, cytokeratin 18 caspase-cleaved fragment; I-FABP, Intestinal fatty acid-binding protein; SCD14, soluble CD14. The cut-off values were calculated as the mean values plus 2 standard deviations of serum levels of individual markers tested in 41 healthy controls.

We found statistically significantly elevated levels of cCK-18 and I-FABP also in patients with T2D $(\mathrm{P}<0.001, \quad \mathrm{P}<0.001), \quad \mathrm{T} 1 \mathrm{D} \quad(\mathrm{P}<0.001, \quad \mathrm{P}<0.001)$, and T1D/INS $(\mathrm{P}<0.01, \mathrm{P}<0.001)$ in comparison with healthy controls. Interestingly, in patients with $\mathrm{T} 2 \mathrm{D}$ the serum levels of cCK-18 were high $(355.4 \pm 287.5 \mathrm{pM})$ and approximately equal to the values in untreated CLD patients. The fraction of 9 out of 30 patients with T2D exceeded the cut-off value for this marker. Moreover, 26 out of 30 T2D patients exhibited various degrees of liver steatosis (all of 9 patients seropositive for cCK-18 had a high degree of liver steatosis), none of untreated CLD patients manifested liver steatosis. In comparison with untreated CLD and T2D, the level of CCK-18 in T1D and 
T1D/INS cohorts was lower: 200.5 \pm 84.3 pM and $204.1 \pm 109.5 \mathrm{pM}$. The frequency of patients seropositive for individual markers in the remaining group was low: 3 out of 20 T1D/INS and 3 out of 20 T1D for cCK-18, 5 out of 20 T1D and 2 out of 20 T1D/INS for I-FABP and none of 30 T2D for I-FABP. We did not find statistically significant differences among the mean levels of cCK-18, I-FABP, and SCD14 in T1D and T1D/INS patients.

\section{Discussion}

In our study, significantly elevated levels of serological markers of epithelial apoptosis (cCK-18) and enterocyte damage (I-FABP) were present in all patient cohorts, i.e. CLD, T1D, T1D/INS and T2D, indicating more extensive epithelium and enterocyte damage in these patients relative to healthy individuals. Our results document that serum levels of cCK-18 and I-FABP are lower in CLD-GFD patients compared with newly diagnosed (untreated) CLD, but slightly elevated levels of these markers persist in CLD-GFD patients. Adriaanse et al. (2013) documented significantly elevated serum levels of I-FABP in patients with active CLD, which decreased after introduction of GFD; however, the reduced values were not within the range observed in healthy controls despite the normalization of IgA anti-tTG Ab. Unfortunately, histological recovery in CLD patients on GFD is often incomplete or absent in a substantial subgroup of patients (Wahab et al. 2002). However, the absence of clinical symptoms and serological markers of CLD, despite their seropositivity for cCK-18 and IFABP, did not allow us to perform small intestinal biopsy in these patients on GFD. A conclusive evidence of increased enterocyte apoptosis and damaged gut mucosal barrier was found only in untreated CLD patients (Shalimar et al. 2013).

We found for the first time significantly elevated levels of serum sCD14 in the cohort of untreated CLD patients. The increasing sCD14 serum levels could be the consequence of involvement of innate immunity cells after translocation of commensal bacteria; alternatively, the sCD14 could originate in enterocytes (Funda et al. 2001). Interestingly, the serum levels of sCD14 were low in patients with T2D who were not treated with rosiglitazone, which is known to reduce CD14 leukocyte expression in these patients (Štulc et al. 2014).

The association of etiopathogenesis of T1D and T2D with impairment of intestinal physiological functions is generally accepted (Vaarala 2008, Baggio and Drucker 2002). Even though T1D a T2D differ in pathogenesis and manifestation clear association between the pathogenesis of these diseases exists and alteration of intestinal mucosa, as well as the assumption concerning the induction of diabetes as a consequence of alteration in the barrier function of small gut mucosa, was suggested (Westerholm-Ormio et al. 2003). The morphological and functional alterations of small intestinal mucosa accompanied by increasing number of goblet cells or depletion of Cajal cells occur in both diseases (Rayner and Horowitz 2006, Zhao et al. 2006). The T1D and T2D are also associated with intestinal motility impairment induced by hyperglycemia-related diabetic autonomic neuropathy leading to chymus retention, dysfunction of intestinal barrier, leaky gut and dysbiosis manifested by constipation or diarrhoea (Virally-Monod et al. 1998, Damci et al. 2003, Shakil et al. 2008). Although acute hyperglycemia has no effect on duodenal pressure waves and flow events, long-lasting hyperglycemia may lead to disruption of the barrier function of the intestine and penetration of luminal food and bacterial antigens into the lymphatic system and blood circulation (Kuo et al. 2010). The possibility of damage of gut mucosa in T2D patients and obese patients suggests pro-inflammatory status documented by production of TNF- $\alpha$, CRP and polarizing cytokine for TH1 response - IL-12 (Hotamisligil and Erbay 2008). In the light of these facts the increased levels of serum markers cCK-18 and I-FABP in diabetic patients could reflect increased enterocyte apoptosis and damage in these patients. On the other hand, several authors documented that elevated levels of cCK-18 could be also the consequence of associated hepatopathy autoimmune hepatopathy in CLD or liver steatosis in T2D (Alavi Moghaddam et al. 2013, Singh et al. 2013, Drastich et al. 2012, Bantel et al. 2001). These observations correspond to our findings of a high prevalence of liver steatosis in the cohort of T2D patients seropositive for cCK-18 marker. The testing of serum cCK-18 is used as prognostic and pharmacodynamic biomarker in patients with colorectal cancer (Greystoke et al. 2012) as well as non-invasive prediction marker of development of liver disorders in T2D (Morling et al. 2014). Interestingly, increased levels of I-FABP were found also in obese humans with chronic hyperglycemia (Verdam et al. 2011). Moreover, I-FABP gene polymorphism (Thr54) is associated with insulin resistance after high monounsaturated fat diet in obese non-diabetic patients (de Luis et al. 2013).

On the basis of our results we can conclude that 
cCK-18 and I-FABP represent sensitive non-invasive serological markers of epithelial apoptosis and damage. For this reason, the detection of serum levels of these molecules and SCD14 could be beneficial for monitoring CLD patients' course after introduction of GFD or as complementary markers for atypical, seronegative forms of CLD. The elevation of cCK-18 and I-FABP in some patients with T2D, T1D and T1D/INS supports the hypothesis that also intestinal damage could be involved in the pathology of diabetes. However, the clinical usefulness of testing cCK-18 and I-FABP in diabetes remains to be confirmed in large-scale studies.

\section{Conflict of Interest}

There is no conflict of interest.

\section{Acknowledgements}

The work was supported by projects 13-14608S and P304/11/1252 of the Czech Science Foundation, NT/13483 of Internal Grant Agency of the Ministry of Health of the Czech Republic, TA01010737 and TA04010762 of Technology Agency of the Czech Republic, and Institutional Research Concept RVO: 61388971.

\section{References}

ADRIAANSE MP, TACK GJ, PASSOS VL, DAMOISEAUX JG, SCHREURS MW, VAN WIJCK K, RIEDL RG, MASCLEE AA, BUURMAN WA, MULDER CJ, VREUGDENHIL AC: Serum I-FABP as marker for enterocyte damage in coeliac disease and its relation to villous atrophy and circulating autoantibodies. Aliment Pharmacol Ther 37: 482-490, 2013.

ALAVI MOGHADDAM M, ROSTAMI NEJAD M, SHALMANI HM, ROSTAMI K, NAZEMALHOSSEINI MOJARAD E, ALDULAIMI D, ZALI MR: The effects of gluten-free diet on hypertransaminasemia in patients with celiac disease. Int J Prev Med 4: 700-704, 2013.

ANCUTA P, KAMAT A, KUNSTMAN KJ, KIM EY, AUTISSIER P, WURCEL A, ZAMAN T, STONE D, MEFFORD M, MORGELLO S, SINGER EJ, WOLINSKY SM, GABUZDA D: Microbial translocation is associated with increased monocyte activation and dementia in AIDS patients. PLoS One 3: e2516, 2008.

ASHABANI A, ABUSHOFA U, ABUSREWILl S, ABDELAZEZ M, TUČKOVÁ L, TLASKALOVÁ-HOGENOVÁ $\mathrm{H}$ : The prevalence of coeliac disease in Libyan children with type 1 diabetes mellitus. Diabetes Metab Res Rev 19: 69-75, 2003.

BAGGIO LL, DRUCKER DJ: Harnessing the therapeutic potential of glucagon-like peptide-1: a critical review. Treat Endocrinol 1: 117-125, 2002.

BANTEL H, RUCK P, GREGOR M, SCHULZE-OSTHOFF K: Detection of elevated caspase activation and early apoptosis in liver diseases. Eur J Cell Biol 80: 230-239, 2001.

BRUEWER M, UTECH M, IVANOV AI, HOPKINS AM, PARKOS CA, NUSRAT A: Interferon-gamma induces internalization of epithelial tight junction proteins via a macropinocytosis-like process. FASEB $J$ 19: 923-933, 2005.

CERUTTI F, BRUNO G, CHIARELLI F, LORINI R, MESCHI F, SACCHETTI C: Younger age at onset and sex predict celiac disease in children and adolescents with type 1 diabetes: an Italian multicenter study. Diabetes Care 27: 1294-1298, 2004.

DAMCI T, NUHOGLU I, DEVRANOGLU G, OSAR Z, DEMIR M, ILKOVA H: Increased intestinal permeability as a cause of fluctuating postprandial blood glucose levels in Type 1 diabetic patients. Eur J Clin Invest 33: $397-$ $401,2003$.

DE LUIS DA, ALLER R, IZAOLA O, GONZALEZ SAGRADO M, CONDE R: Fatty acid-binding protein 2 Ala54Thr genotype is associated with insulin resistance and leptin levels changes after a high monounsaturated fat diet in obese non-diabetic patients. J Endocrinol Invest 36: 402-406, 2013.

DERIKX JP, MATTHIJSEN RA, DE BRUÏNE AP, VAN BIJNEN AA, HEINEMAN E, VAN DAM RM, DEJONG CH, BUURMAN WA: Rapid reversal of human intestinal ischemia-reperfusion induced damage by shedding of injured enterocytes and reepithelialisation. PLoS One 3: e3428, 2008. 
DRASTICH P, HONSOVÁ E, LODEREROVÁ A, JAREŠOVÁ M, PEKÁRIKOVÁ A, HOFFMANOVÁ I, TUČKOVÁ L, TLASKALOVÁ-HOGENOVÁ H, ŠPIČÁK J, SÁNCHEZ D: Celiac disease markers in patients with liver diseases: a single center large scale screening study. World J Gastroenterol 18: 6255-6262, 2012.

FASANO A, SHEA-DONOHUE T: Mechanisms of disease: the role of intestinal barrier function in the pathogenesis of gastrointestinal autoimmune diseases. Nat Clin Pract Gastroenterol Hepatol 2: 416-422, 2005.

FUNDA DP, TUČKOVÁ L, FARRÉ MA, IWASE T, MORO I, TLASKALOVÁ-HOGENOVÁ H: CD14 is expressed and released as soluble CD14 by human intestinal epithelial cells in vitro: lipopolysaccharide activation of epithelial cells revisited. Infect Immun 69: 3772-3781, 2001.

GREYSTOKE A, DEAN E, SAUNDERS MP, CUMMINGS J, HUGHES A, RANSON M, DIVE C, RENEHAN AG: Multi-level evidence that circulating CK18 is a biomarker of tumor burden in colorectal cancer. $\mathrm{Br} J \mathrm{Cancer}$ 107: 1518-1524, 2012.

HOTAMISLIGIL GS, ERBAY E: Nutrient sensing and inflammation in metabolic diseases. Nat Rev Immunol 8: 923934, 2008.

HUMMEL S, PFLÜGER M, HUMMEL M, BONIFACIO E, ZIEGLER AG: Primary dietary intervention study to reduce the risk of islet autoimmunity in children at increased risk for type 1 diabetes: the BABYDIET study. Diabetes Care 34: 1301-1305, 2011.

HUSBY S, KOLETZKO S, KORPONAY-SZABÓ IR, MEARIN ML, PHILLIPS A, SHAMIR R, TRONCONE R, GIERSIEPEN K, BRANSKI D, CATASSI C, LELGEMAN M, MÄKI M, RIBES-KONINCKX C, VENTURA A, ZIMMER KP: European Society for Pediatric Gastroenterology, Hepatology, and Nutrition guidelines for the diagnosis of coeliac disease. J Pediatr Gastroenterol Nutr 54: 136-160, 2012.

KNIP M, SIMELL O: Environmental triggers of Type 1 diabetes. Cold Spring Harb Perspect Med 2: a007690, 2012.

KNIP M, VEIJOLA R, VIRTANEN SM, HYÖTY H, VAARALA O, AKERBLOM HK: Environmental triggers and determinats of type 1 diabetes. Diabetes 54 (Suppl 2): S125-S136, 2005.

KRÁLOVÁ LESNÁ I, SUCHÁNEK P, BRABCOVÁ E, KOVÁŘ J, MALÍNSKÁ H, POLEDNE R: Effect of different types of dietary fatty acids on subclinical inflammation in humans. Physiol Res 62: 145-152, 2013.

KUČERA P, NOVÁKOVÁ D, BEHANOVÁ M, NOVÁK J, TLASKALOVÁ-HOGENOVÁ H, ANDĚL M: Gliadin, endomysial and thyroid antibodies in patients with latent autoimmune diabetes of adults (LADA). Clin Exp Immunol 133: 139-143, 2003.

KUO P, WISHART JM, BELLON M, SMOUT AJ, HOLLOWAY RH, FRASER RJ, HOROWITZ M, JONES KL, RAYNER CK: Effects of physiological hyperglycemia on duodenal motility and flow events, glucose absorption, and incretin secretion in healthy humans. J Clin Endocrinol Metab 95: 3893-3900, 2010.

LETTRE G, RIOUX JD: Autoimmune diseases: insights from genome-wide association studies. Hum Mol Genet 17: 116-121, 2008.

LI Q, ZHANG Q, WANG M, ZHAO S, MA J, LUO N, LI N, LI Y, XU G, LI J: Interferon-gamma and tumor necrosis factor-alpha disrupt epithelial barrier function by altering lipid composition in membrane microdomains of tight junction. Clin Immunol 126: 67-80, 2008.

MORLING JR, FALLOWFIELD JA, WILLIAMSON RM, NEE LD, JACKSON AP, GLANCY S, REYNOLDS RM, HAYES PC, GUHA IN, STRACHAN MW, PRICE JF: Non-invasive hepatic biomarkers (ELF and CK18) in people with type 2 diabetes: the Edinburgh type 2 diabetes study. Liver Int 34: 1267-1277, 2014.

MUSSO G, GAMBINO R, CASSADER M: Obesity, diabetes, and gut microbiota: The hygiene hypothesis expanded? Diabetes Care 33: 2277-2284, 2010.

NOKOFF NJ, REWERS M, CREE GREEN M: The interplay of autoimmunity and insulin resistance in type 1 diabetes. Discov Med 13: 115-122, 2012.

OSTERBYE T, FUNDA DP, FUNDOVÁ P, MÅNSSON JE, TLASKALOVÁ-HOGENOVÁ H, BUSCHARD K: A subset of human pancreatic beta cells express functional CD14 receptors: a signaling pathway for beta cellrelated glycolipids, sulfatide and $\beta$-galactosylceramide. Diabetes Metab Res Rev 26: 656-667, 2010. 
PENG H, HAGOPIAN W: Environmental factors in the development of Type 1 diabetes. Rev Endocr Metab Disord 7 : 149-162, 2006.

PHAM-SHORT A, DONAGHUE KC, AMBLER G, CHAN AK, CRAIG ME: Coeliac disease in Type 1 diabetes from 1990 to 2009: higher incidence in young children after longer diabetes duration. Diabet Med 29: e286-e289, 2012.

RAYNER CK, HOROWITZ M: Gastrointestinal motility and glycemic control in diabetes: the chicken and the egg revisited? J Clin Invest 116: 299-302, 2006.

REWERS M, EISENBARTH GS: Autoimmunity: Celiac disease in T1DM - the need to look long term. Nat Rev Endocrinol 8: 7-8, 2011.

REWERS M, LIU E, SIMMONS J, REDONDO MJ, HOFFENBERG EJ: Celiac disease associated with type 1 diabetes mellitus. Endocrinol Metab Clin North Am 33: 197-214, 2004.

SALARDI S, VOLTA U, ZUCCHINI S, FIORINI E, MALTONI G, VAIRA B, CICOGNANI A: Prevalence of celiac disease in children with type 1 diabetes mellitus increased in the mid-1990s: an 18-year longitudinal study based on anti-endomysial antibodies. J Pediatr Gastroenterol Nutr 46: 612-614, 2008.

SHAKIL A, CHURCH RJ, RAO SS: Gastrointestinal complications of diabetes. Am Fam Physician 77: 1697-1702, 2008.

SHALIMAR DM, DAS P, SREENIVAS V, GUPTA SD, PANDA SK, MAKHARIA GK: Mechanism of villous atrophy in celiac disease: role of apoptosis and epithelial regeneration. Arch Pathol Lab Med 137: 1262-1269, 2013.

SINGH P, AGNIHOTRI A, JINDAL G, SHARMA PK, SHARMA M, DAS P, GUPTA D, MAKHARIA GK: Celiac disease and chronic liver disease: is there a relationship? Indian J Gastroenterol 32: 404-408, 2013.

ŠTULC T, SVOBODOVÁ H, KRUPIČKOVÁ Z, DOLEŽALOVÁ R, MARINOV I, ČEŠKA R. Rosiglitazone influences the expression of leukocyte adhesion molecules and CD14 receptor in type 2 diabetes mellitus patients. Physiol Res 63 (Suppl 2): S293-S298, 2014.

TLASKALOVÁ-HOGENOVÁ H, ŠTĚPÁNKOVÁ R, KOZÁKOVÁ H, HUDCOVIC T, VANNUCCI L, TUČKOVÁ L, ROSSMANN P, HRNČÍŘ T, KVERKA M, ZÁKOSTELSKÁ Z, KLIMEŠOVÁ K, PŘIBYLOVÁ J, BÁRTOVÁ J, SÁNCHEZ D, FUNDOVÁ P, BOROVSKÁ D, ŠRŮTKOVÁ D, ZÍDEK Z, SCHWARZER M, DRASTICH P, FUNDA DP: The role of gut microbiota (commensal bacteria) and the mucosal barrier in the pathogenesis of inflammatory and autoimmune diseases and cancer: contribution of germ-free and gnotobiotic animal models of human diseases. Cell Mol Immunol 8: 110-120, 2011.

TRIER JS: Celiac sprue: $N$ Engl J Med 325: 1709-1719, 1991.

VAARALA O: Leaking gut in type 1 diabetes. Curr Opin Gastroenterol 24: 701-706, 2008.

VERDAM FJ, GREVE JW, ROOSTA S, VAN EIJK H, BOUVY N, BUURMAN WA, RENSEN SS: Small intestinal alterations in severely obese hyperglycemic subjects. J Clin Endocrinol Metab 96: e379-e383, 2011.

VIRALLY-MONOD M, TIELMANS D, KEVORKIAN JP, BOUHNIK Y, FLOURIE B, POROKHOV B, AJZENBERG C, WARNET A, GUILLAUSSEAU PJ: Chronic diarrhoea and diabetes mellitus: prevalence of small intestinal bacterial overgrowth. Diabetes Metab 24: 530-536, 1998.

WAHAB PJ, MEIJER JW, MULDER CJ: Histologic follow-up of people with celiac disease on a gluten-free diet: slow and incomplete recovery. Am J Clin Pathol 118: 459-463, 2002.

WANG Y, LI J, TANG L, WANG Y, CHARNIGO R, DE VILLIERS W, ECKHARDT E: T-lymphocyte responses to intestinally absorbed antigens can contribute to adipose tissue inflammation and glucose intolerance during high fat feeding. PLoS One 5: e13951, 2010.

WENZLAU JM, JUHL K, YU L, MOUA O, SARKAR SA, GOTTLIEB P, REWERS M, EISENBARTH GS, JENSEN J, DAVIDSON HW, HUTTON JC: The cation efflux transporter ZnT8 (Slc30A8) is a major autoantigen in human type 1 diabetes. Proc Natl Acad Sci USA 104: 17040-17045, 2007.

WESTERHOLM-ORMIO M, VAARALA O, PIHKALA P, ILONEN J, SAVILAHTI E: Immunologic activity in the small intestinal mucosa of pediatric patients with type 1 diabetes. Diabetes 52: 2287-2295, 2003. 
YAJIMA S, MORISAKI H, SERITA R, SUZUKI T, KATORI N, ASAHARA T, NOMOTO K, KOBAYASHI F, ISHIZAKA A, TAKEDA J: Tumor necrosis factor-alpha mediates hyperglycemia-augmented gut barrier dysfunction in endotoxemia. Crit Care Med 37: 1024-1030, 2009.

ZHAO J, FRØKJAER JB, DREWES AM, EJSKJAER N: Upper gastrointestinal sensory-motor dysfunction in diabetes mellitus. World J Gastroenterol 12: 2846-2857, 2006.

ZHERNAKOVA A, WITHOFF S, WIJMENGA C: Clinical implications of shared genetics and pathogenesis in autoimmune diseases. Nat Rev Endocrinol 9: 646-659, 2013. 